\title{
Relationship between the Reinforcement Size and Mechanical Properties of Zr-Based Glassy Matrix Composites
}

\author{
Zhenhua Chu ${ }^{1,2}$, Hidemi Kato ${ }^{2}$, Takeshi $\mathrm{Wada}^{2}$, Guoqiang $\mathrm{Xie}^{2}$, \\ Guangyin Yuan ${ }^{1,3, *}$ and Wenjiang Ding ${ }^{1,3}$ \\ ${ }^{1}$ National Engineering Research Center of Light Alloy Net Forming, Shanghai Jiao Tong University, Shanghai, 200240, P. R. China \\ ${ }^{2}$ Institute for Materials Research, Tohoku University, Sendai 980-8577, Japan \\ ${ }^{3}$ Key State Laboratory of Metal Matrix Composite, Shanghai Jiao Tong University, Shanghai, 200240, P. R. China
}

\begin{abstract}
Large-size of $\mathrm{Zr}_{55} \mathrm{Cu}_{30} \mathrm{Al}_{10} \mathrm{Ni}_{5}$ glassy alloy composites (GACs) containing TiNb particles were fabricated by spark plasma sintering (SPS) process. Large plasticity and high strength were obtained due to addition of TiNb particles. Two kinds of TiNb particles with different particle size were introduced into glassy matrix. The GACs samples reinforced by smaller particles showed higher strength and larger plasticity. The GACs with the addition of TiNb particles exhibit similar thermal properties in comparison with the glassy matrix alloy. No other crystalline phase besides TiNb was detected in the composites and good bonding state between TiNb and glassy matrix was observed. [doi:10.2320/matertrans.M2011367]
\end{abstract}

(Received November 28, 2011; Accepted February 23, 2012; Published April 18, 2012)

Keywords: glassy alloy composite, spark plasma sintering, compression test, plasticity

\section{Introduction}

Bulk metallic glasses (BMGs) exhibit particular advantages such as high strength, high hardness, superior corrosion resistance, but they are unsuitable for structural applications. The reason is that most of BMGs display very limited plasticity at room temperature normally less than $2 \%$ in compression and nearly $0 \%$ in tension. ${ }^{1)}$ In general, poor ductility of BMGs is attributed to inhomogeneous flow and formation of highly localized shear bands in narrow regions. The localization of shear bands is associated with "strainsoftening"1) which makes the initiation of the shear band and its propagation takes place almost simultaneously and leads to cracks develop quickly and catastrophic failure. As such, more and more researchers have focused on improving the plasticity of BMGs by introduction nano- or micro-scale crystalline phases into the metallic glassy matrix in order to form multiple shear bands. ${ }^{2-7)}$

Many researchers reported the fabrication of the GACs with the addition of crystalline particles, such as $\mathrm{SiC}, \mathrm{Al}_{2} \mathrm{O}_{3}$, $\mathrm{ZrO}_{2}, \mathrm{~W}, \mathrm{Si}_{3} \mathrm{~N}_{4}$, Ta and so on, , $\left.3,8-12\right)^{2}$ and gained exiting results. Furthermore, we note that the effect of reinforcement on plasticity improvement of BMGs is correlated to the microstructure of the reinforcement. Cheng ${ }^{13)}$ and Sun ${ }^{14)}$ pointed out that the size and morphology of the precipitated crystalline phase affect the mechanical property of BMG matrix.

For the method of fabricating GACs, casting techniques were adopted by most of researchers, which limits the dimension and affects the glassy formation ability (GFA) of glassy alloy composites (GACs). Therefore, the development of appropriate techniques is necessary to fabricate large-size GACs. Spark plasma sintering (SPS) technique can sinter powders to a full density sample at relatively low temperatures in a short sintering time. ${ }^{15)}$ It has been used as one of promising methods to fabricate BMGs. Xie ${ }^{16)}$ obtained nearly

*Corresponding author, E-mail: gyyuan@sjtu.edu.cn
$100 \%$ relative density $\mathrm{Ni}_{52.5} \mathrm{Nb}_{10} \mathrm{Zr}_{15} \mathrm{Ti}_{15} \mathrm{Pt}_{7.5}$ bulk metallic glass by SPS and Sergio Scudino ${ }^{17)}$ reported that highstrength Al-based bulk material could be got by SPS consolidated glassy powders.

In this work, GACs of $\mathrm{Zr}_{55} \mathrm{Cu}_{30} \mathrm{Al}_{10} \mathrm{Ni}_{5}$ glassy matrix reinforced by ductile $\beta$-TiNb particle was fabricated by SPS successfully. There are two kinds of particle size for the additional $\mathrm{TiNb}$ particle. The effect of $\mathrm{TiNb}$ particle size on the yield strength and plasticity of GACs were investigated systematically. Meanwhile, the structure, thermal stability of GACs as well as the interface of matrix and $\mathrm{TiNb}$ was studied.

\section{Experimental Procedures}

Master ingots of the $\mathrm{Zr}_{55} \mathrm{Cu}_{30} \mathrm{Al}_{10} \mathrm{Ni}_{5}$ alloy were prepared by arc melting. In order to obtain $\mathrm{Zr}_{55} \mathrm{Cu}_{30} \mathrm{Al}_{10} \mathrm{Ni}_{5}$ glassy powders, the $\mathrm{Zr}_{55} \mathrm{Cu}_{30} \mathrm{Al}_{10} \mathrm{Ni}_{5}$ ingots were remelted in a quartz tube using an induction heating coil under vacuum. The melts were injected through a nozzle and atomization by high pressure helium gas. The $\mathrm{Zr}_{55} \mathrm{Cu}_{30} \mathrm{Al}_{10} \mathrm{Ni}_{5}$ glassy powders were sieved to below $53 \mu \mathrm{m}$ and mixed with designated content of $\mathrm{TiNb}$ (48.9 : 51.1 mass \%) particles with particle size of $53-106 \mu \mathrm{m}$ and $20-53 \mu \mathrm{m}$ in a mixer for over $48 \mathrm{~h}$. Blended $\mathrm{Zr}_{55} \mathrm{Cu}_{30} \mathrm{Al}_{10} \mathrm{Ni}_{5}$ and $\mathrm{TiNb}$ powders were sintered in a vacuum condition using a SPS system (Model SPS-3.20MK-IV). The blended powders were heated from room temperature to $30 \mathrm{~K}$ below sintering temperature at $50 \mathrm{k} / \mathrm{min}$ and slowly heated to sintering temperature $(623 \mathrm{~K})$ at $5 \mathrm{k} / \mathrm{min}$ for $10 \mathrm{~min}$, under uniaxial pressure of $600 \mathrm{MPa}$.

The structures of the gas-atomized powders and sintered samples were investigated by X-ray diffraction (XRD) method using a $\mathrm{Cu} \mathrm{K} \alpha$ source. And the thermal stability of the powders and the sintered samples were investigated by differential scanning calorimetry (DSC) at a heating rate of $0.67 \mathrm{~K} \mathrm{~s}^{-1}$ under a continuous flow of purified argon. The compressive mechanical properties were measured with an Instron 4201 mechanical test system at room temperature and 

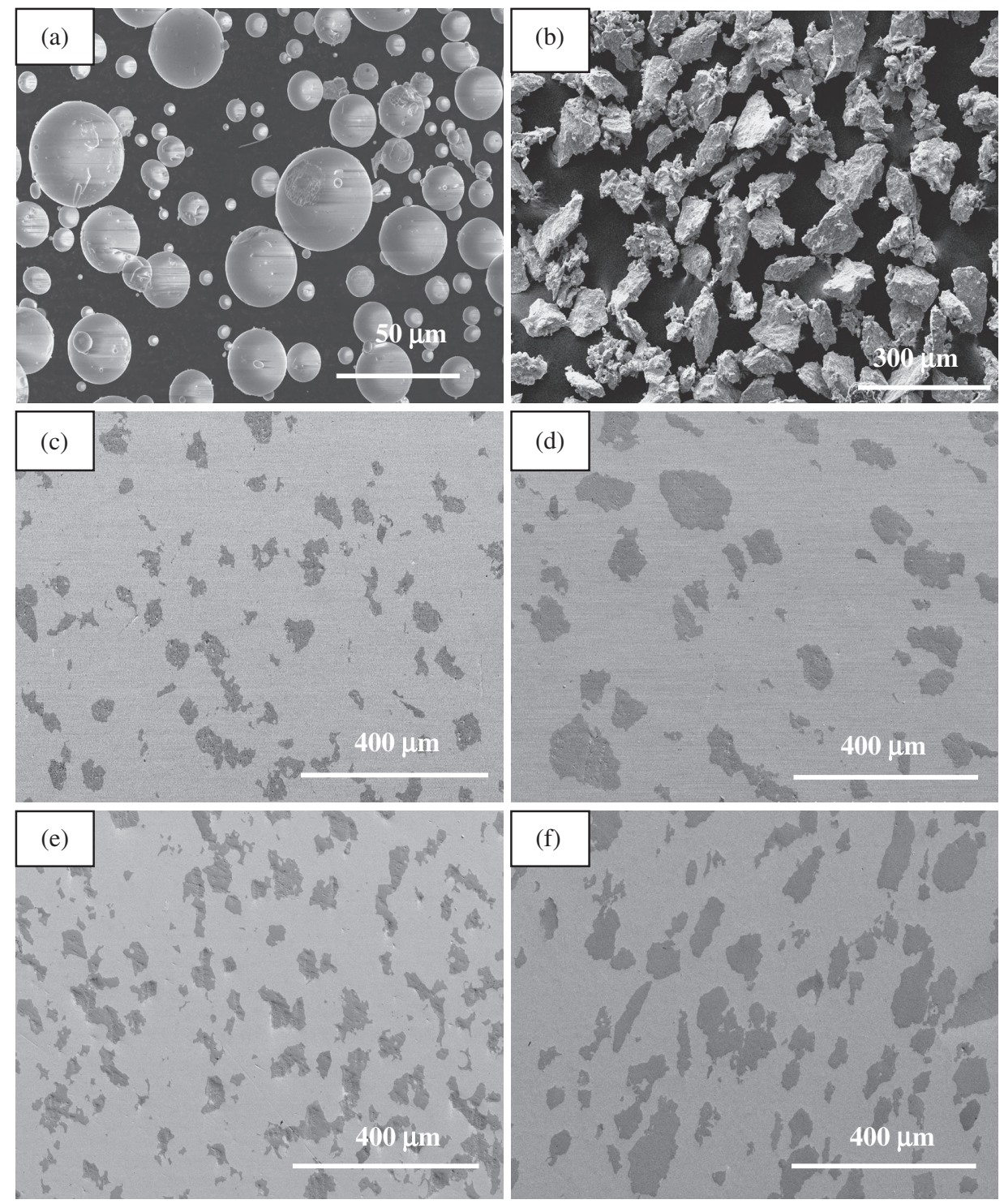

Fig. 1 SEM micrographs of glassy powders (a); TiNb powders (b); and GACs specimens reinforced by TiNb particles with particle size of 20-53 $\mu \mathrm{m} 5 \mathrm{vol} \%$ (c); $20 \mathrm{vol} \%$ (d) and with TiNb particle size of $53-106 \mu \mathrm{m} 5 \mathrm{vol} \%$ (e); $20 \mathrm{vol} \%$ (f).

the initial strain rate was $5 \times 10^{-4} \mathrm{~s}^{-1}$. The gauge dimensions of compressive test specimens were $2.5 \mathrm{~mm}$ in width, $2.5 \mathrm{~mm}$ in thickness and $5 \mathrm{~mm}$ in length. The microstructures of the glassy alloy composites were characterized by scanning electron microscopy (SEM). Microstructure of the interface between matrix and $\mathrm{TiNb}$ particle was studied by conventional and high-resolution transmission electron microscopy (TEM and HRTEM). Thin foil specimens were cut from the sintered specimens. In this study, a low-energy ion milling at about $2.0 \mathrm{keV}$ was used to avoid the ion-beam induced crystallization. TEM was carried out using a JEM-2010 (JEOL) electron microscope operating at $200 \mathrm{kV}$.

\section{Results}

Figure 1 shows SEM micrographs of the gas-atomized powders, TiNb particles and the cross section of the GACs specimens containing different volume fractions and particle sizes of $\mathrm{TiNb}$ particles. It can be seen that $\mathrm{TiNb}$ particles are homogeneously dispersed in the glassy matrix. There is a good bonding between the matrix and the TiNb particles and no other crystalline phase in $\mathrm{Zr}_{55} \mathrm{Cu}_{30} \mathrm{Al}_{10} \mathrm{Ni}_{5}$ glassy matrix is observed.

The structures of gas-atomized $\mathrm{Zr}_{55} \mathrm{Cu}_{30} \mathrm{Al}_{10} \mathrm{Ni}_{5}$ glassy powders and GACs were studied by XRD. As shown in Fig. 2(a), the original $\mathrm{Zr}_{55} \mathrm{Cu}_{30} \mathrm{Al}_{10} \mathrm{Ni}_{5}$ glassy powder $(\mathrm{TiNb}=0)$ shows only a diffuse diffraction pattern of typical amorphous phase, while the patterns of the GACs samples show sharp peaks belonging to $\mathrm{TiNb}$ particulates superimposed on a broad halo peak, which indicates that the matrix is a fully glassy phase. Meanwhile, it also implies that the addition of $\mathrm{TiNb}$ particles does not affect the matrix composition.

Figure 2(b) shows the DSC curves of the gas-atomized powders and GACs samples. The features of the DSC curves are all similar, namely, an endothermic reaction due to the glass transition, followed by a large supercooled liquid region and one exothermic reaction due to crystallization events. The glass transition temperature $\left(T_{\mathrm{g}}\right)$ of the GACs samples is close to that of the glassy powder, which is $684 \mathrm{~K}$. While 


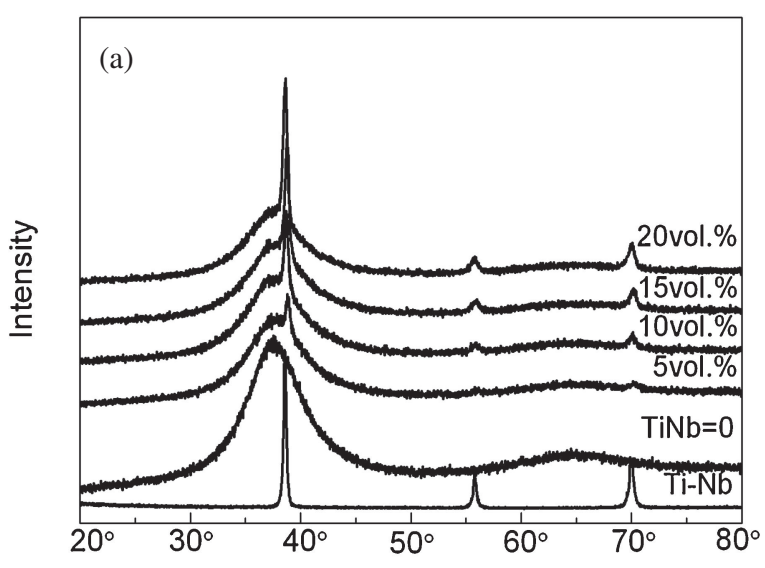

$2 \theta$

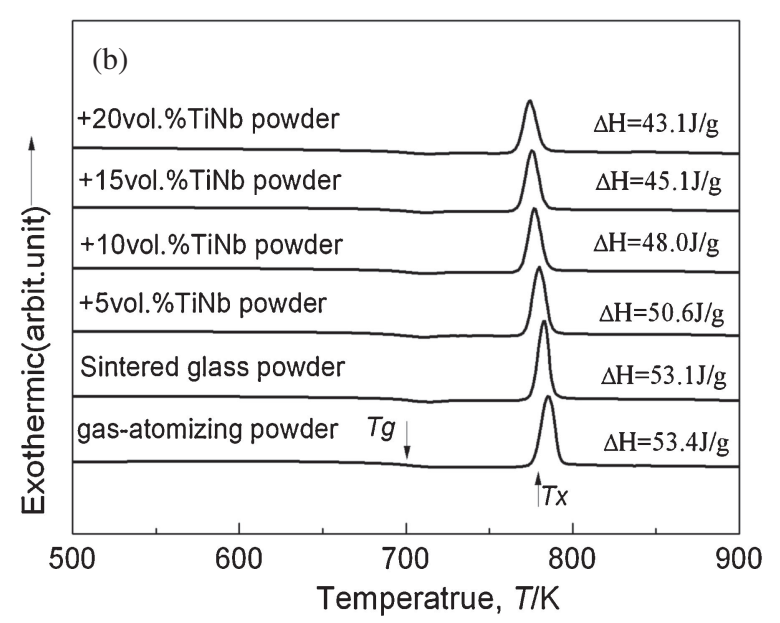

Fig. 2 XRD patterns of GACs specimens with various TiNb contents (a) and that of $\mathrm{TiNb}$ particles; DSC curves of the gas-atomizing powder, sintered monolithic $\mathrm{Zr}_{55} \mathrm{Cu}_{30} \mathrm{Al}_{10} \mathrm{Ni}_{5}$ BMG, and GACs specimens with various $\mathrm{TiNb}$ contents (b).

the onset temperature of the first-stage crystallization $\left(T_{\mathrm{x}}\right)$ exhibits a slightly decreasing with increasing volume fraction of $\mathrm{TiNb}$ particles. The influence of the addition of $\mathrm{TiNb}$ on the $T_{\mathrm{g}}$ and $T_{\mathrm{x}}$ may be originated from the increase of heterogeneous nucleation sites from the interface between the glassy matrix and the crystalline TiNb particles. The values of crystallization enthalpy $(\Delta H)$ of the composites decrease with the increase of volume percent of $\mathrm{TiNb}$ particles. It indicates that there is no other crystalline in the composites except TiNb particles.

The interface of matrix and TiNb particle was investigated by TEM. Figure 3 shows TEM images of the interface taken from GACs specimen containing $20 \mathrm{vol} \% \mathrm{TiNb}$ particles with particle size of $20-53 \mu \mathrm{m}$. The bonded interface between particle and glassy matrix was observed, as shown in Fig. 3(a), a bright-field TEM image of the interface, which indicates a good bonding state between them. Figures 3(b) and $3(\mathrm{c})$ are the selected-area diffraction (SAD) patterns corresponding to the areas marked by "A" and "B" in Fig. 3(a) respectively. The halo ring in the SAD pattern of Fig. 3(b) implies a glassy phase of the matrix. Figure 3(c) shows a body-centered cubic lattice in [100] direction, which agrees with the structure of the original $\mathrm{TiNb}$ particles. The bonded interface between the TiNb particle and the matrix is
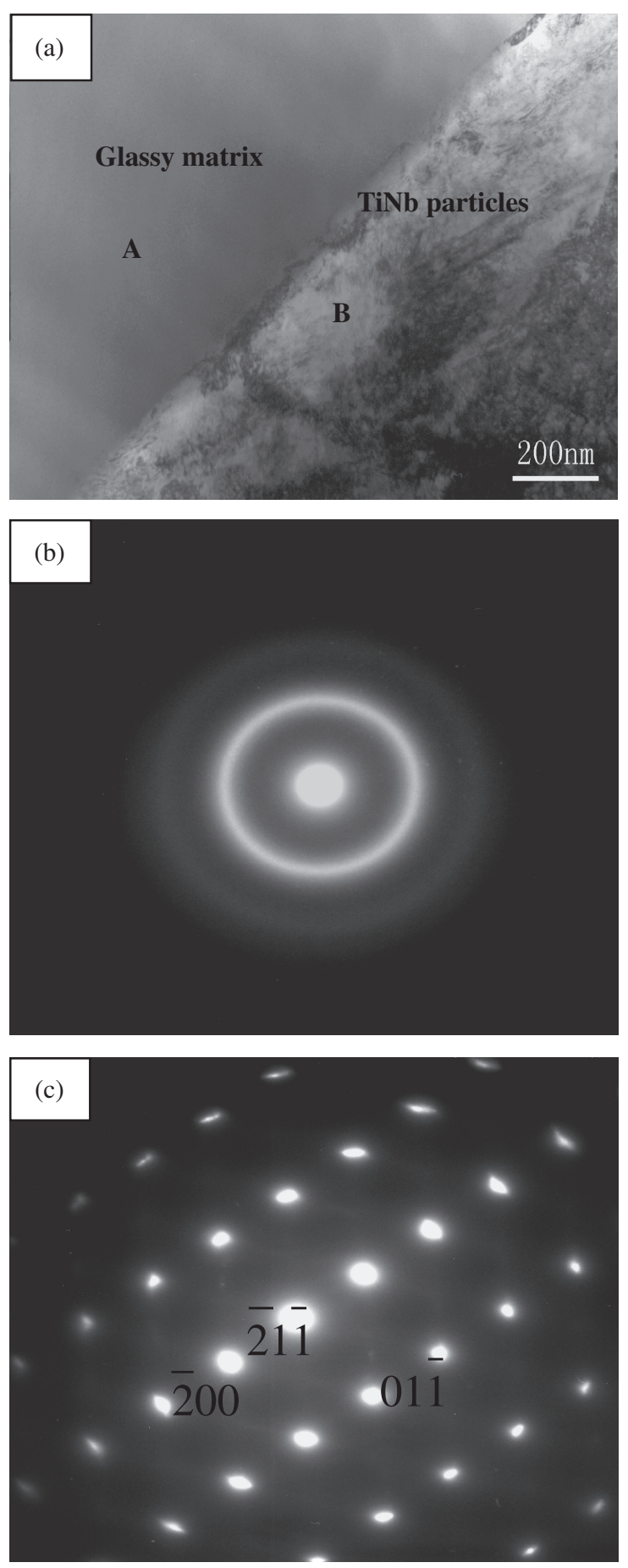

Fig. 3 TEM micrographs of the GACs sample containing 20 vol\% TiNb particle with particle size of $20-53 \mu \mathrm{m}$ : bright-field TEM image (a); SAD patterns taken from the indicated by "A" (b) and "B" (c) in Fig. 3(a) respectively.

clear, as shown in Fig. 3(a). It is to say that there is a good bonding state and no other intermediate crystalline in the interface between the glassy matrix and the $\mathrm{TiNb}$ particle.

The compressive properties of the GACs samples were studied. Figure 4 shows typical compressive stress-strain curves for the GACs specimens with various TiNb contents. Figures 4(a) and 4(b) give the stress-strain curves for the GACs samples with TiNb particles size of $20-53 \mu \mathrm{m}$ and 53$106 \mu \mathrm{m}$ respectively. It indicates that the plasticity of GACs specimen is improved by the addition of TiNb particles, 

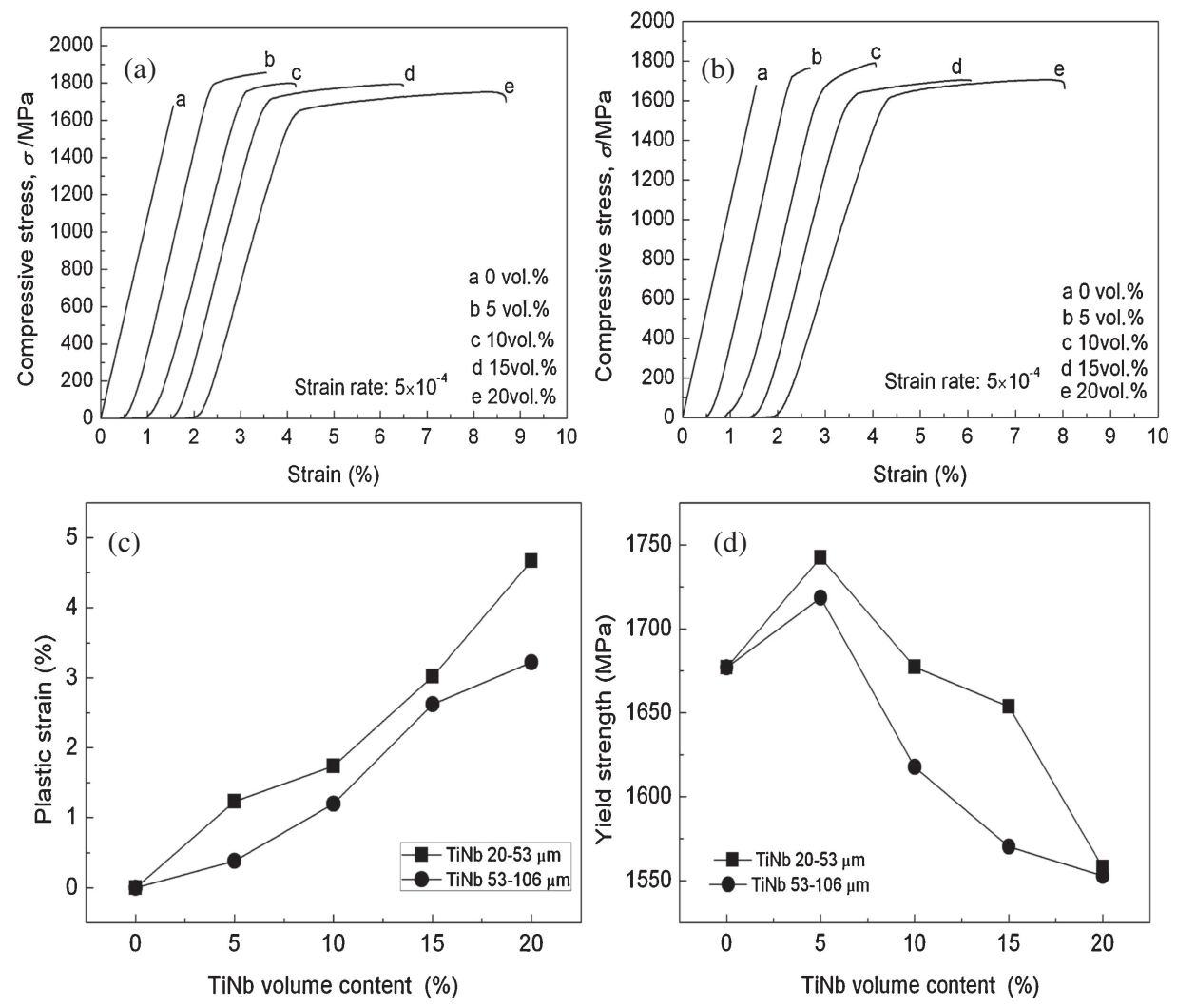

Fig. 4 Compressive stress-strain curves of the GACs specimens with various TiNb contents fabricated by the SPS with the TiNb particle size of 20-53 $\mu \mathrm{m}$ (a) and 53-106 $\mu \mathrm{m}$ (b); Relationship of the TiNb particle sizes with plastic strain (c) and yield strength (d).

meanwhile the plasticity increases with the increase of $\mathrm{TiNb}$ contents. The fracture strengths of the GACs are also higher than that of monolithic metallic glass. On the other hand, the yield strengths of the GACs decrease with the increase of $\mathrm{TiNb}$ contents. Comparing the yield strength and plastic strain between the compression GACs samples reinforced by TiNb with $20-53 \mu \mathrm{m}$ and 53-106 $\mu \mathrm{m}$, the values of the yield strength and plastic strain of GACs specimens with smaller $\mathrm{TiNb}$ particles size are higher than that of GACs samples reinforced by larger particle, as shown in Figs. 4(c) and 4(d).

Figures 5(a)-5(d) show SEM micrographs of the fracture surface and side surface for glassy matrix and a GAC specimen reinforced by 20 vol\% TiNb particles with particle size of $20-53 \mu \mathrm{m}$. Figure 5(a) reveals that the monolithic bulk metallic glass breaks in a split mode. Meanwhile, the GAC specimen breaks in a shear mode, as shown in Figure 5(b). This suggests that the deformation mechanism of the composites has changed comparing with the monolithic bulk metallic glass. Multiple shear bands are uniformly distributed in the compressive sample, as observed in Fig. 5(c). The enhanced plasticity of GACs specimens should be contributed to the formation of multiple shear bands. It can be seen that shear bands are initiated and propagated at the front of TiNb particle, as shown in the insert of Fig. 5(c). Figure 5(d) shows the fracture surface of the compressive sample. This image shows the characteristic vein-like pattern of fracture morphology. The vein-like structure on the failure fracture surface is attributed to localized melting within shear bands, and the direction of the veins is along of the direction of fracture. The size of vein pattern is reduced, which suggests the flow of the material slows at the front of $\mathrm{TiNb}$ particle. Around the sides and front of the particle, smooth surface can be seen, which indicated a fast fracture. ${ }^{18)}$

\section{Discussion}

It is well known that the initiation of the shear band and its propagation takes place almost simultaneously and leads to cracks development quickly and catastrophic failure in monolithic bulk metallic glass. ${ }^{19)}$ The reinforcement can obstruct the development of the shear band in glassy matrix to avoid a catastrophic cracking and fracture. ${ }^{20}$ ) This work shows a directive evidence of shear bands propagation at the front of TiNb particles, as shown in Figs. 5(c) and 5(d). However, at a given volume percent, the plasticity and the yield strength of the composite reinforced by $\mathrm{TiNb}$ with different particle size are different, as shown in Figs. 4(c) and 4(d). The reason of this is originated from the deformation mechanisms of metallic glasses. The accommodation of shear strain in metallic glass under an applied stress, unlike dislocation motion in crystalline alloys, is regarded as the deformation mechanism of metallic glass. The continued propagation of this applied shear strain occurs when one shear transformation zone (STZ) creates a localized distortion of the surrounding material. It is regarded as the fundamental unit of plasticity during inhomogeneous deformation of metallic glasses. ${ }^{21)}$

The Vickers micro hardness of TiNb particles and the glassy matrix were tested. The results are as following: $301.22 \pm 31.81 \mathrm{Hv}$ for TiNb particles $20-53 \mu \mathrm{m}, 251.06 \pm$ $29.86 \mathrm{Hv}$ for $\mathrm{TiNb}$ particles $53-106 \mu \mathrm{m}$, and $699.78 \pm$ $32.89 \mathrm{Hv}$ for glassy matrix, respectively, which are agree 

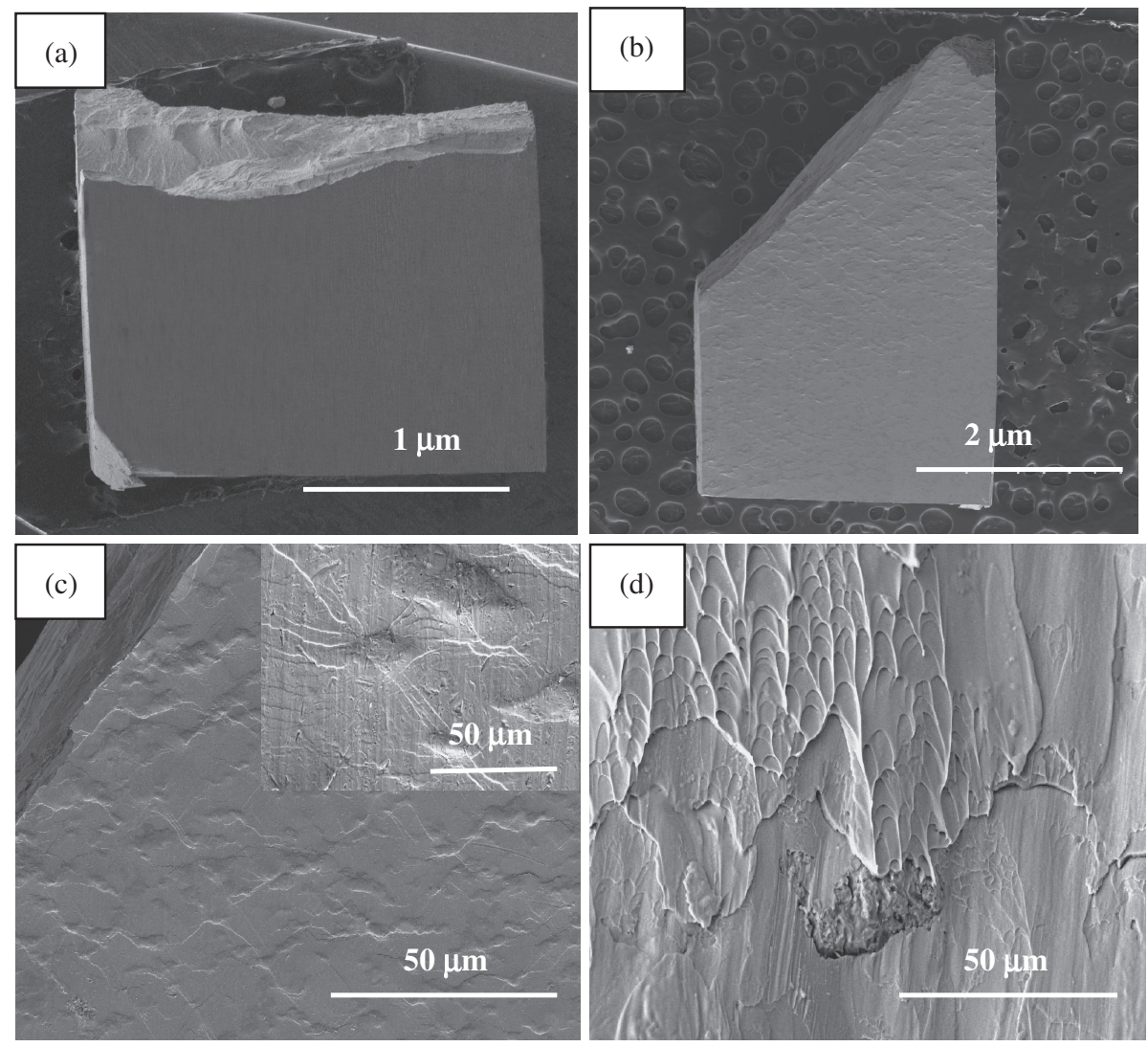

Fig. 5 SEM micrographs of the side surface of $\mathrm{Zr}_{55} \mathrm{Cu}_{30} \mathrm{Al}_{10} \mathrm{Ni}_{5}$ after compression test (a); the side surface after compression test (b)-(c) and fracture surface (d) of the GACs samples reinforced by 20 vol\% TiNb particles with particle size of $20-53 \mu \mathrm{m}$.

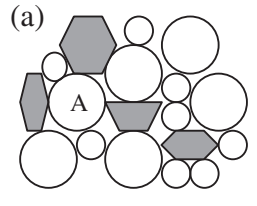

Gray one: $\mathrm{TiNb}$

White one: glassy powder

Fig. 6 Schematic illustration of TiNb particles distribution around glassy powders: TiNb particle size $20-53 \mu \mathrm{m}$ (a) and 53-106 $\mu \mathrm{m}$ (b).

with the previous results. ${ }^{22)}$ It indicates that $\mathrm{TiNb}$ particles yield firstly for the GACs samples during the compressive process. Therefore, stress concentration is introduced into the interface between glassy matrix and $\mathrm{TiNb}$ particle. It is conceptualized that stress concentration at the front of shear band can activate STZs and result in the growth and propagation of the shear band producing macroscopic strain. However, the distribution of the two kinds of reinforcement is different at the same volume percent, as shown in Figs. 6(a) and $6(\mathrm{~b})$. It can be seen that the number of the interface per unit volume of GACs with smaller TiNb particle size is larger than that of GACs with larger particle size. Therefore, the more stress-concentrated area is introduced for the smaller particle. In other words, for the GACs with smaller particle size, the number of reinforcement particles, acting as the impediment of extend of a single shear band and inducing the formation of second shear bands, is larger than that of GACs with larger particle. Hence, TiNb particle with smaller particle size can improve the plasticity of the composites more efficiently. Meanwhile, according to the schematic illustration of the distribution of TiNb particles, as shown in Fig. 6, the $\mathrm{TiNb}$ particles with smaller particle size can constrain the deformation of glassy powders more efficiently, for example glassy powder "A". Thereby, the yield strength of GACs reinforced small TiNb particle is higher than that of large particle.

\section{Conclusion}

Bulk GACs samples of $\mathrm{Zr}_{55} \mathrm{Cu}_{30} \mathrm{Al}_{10} \mathrm{Ni}_{5}$ reinforced by $\mathrm{TiNb}$ particles were fabricated by SPS process. The microstructure and mechanical properties of the GACs samples were investigated. Both fracture strength and the plasticity were improved by the addition of TiNb particles. The process of the deformation for the composites is interaction between $\mathrm{TiNb}$ particles and glassy matrix. The smaller reinforcements introduce the more stress concentration areas which results in propagation of shear bands. The GACs samples reinforced by smaller particle showed higher strength and larger plasticity.

\section{Acknowledgements}

This work was supported by the National Nature Science Foundation of China (No. 50771063), Science and Technology Commission of Shanghai Municipality (No. 10JC1407400), the Ph.D. Programs Foundation of Ministry of Education of China (No. 20100073110004) and Jiangsu Key Laboratory of Advanced Metallic Materials (AMM200903). 


\section{REFERENCES}

1) W. H. Wang, C. Dong and C. H. Shek: Mater.Sci. Eng. R 44 (2004) 45-89.

2) G. Q. Xie, D. V. Louzguine-Luzgin, F. Wakai, H. Kimura and A. Inoue: Mater. Sci. Eng. B 148 (2008) 77-81.

3) G. Q. Xie, D. V. Louzguine-Luzgin, H. Kimura and A. Inoue: Mater. Trans. 48 (2007) 158-162.

4) J. J. Lewandoski, M. Shazly and A. Shamimi: Scr. Mater. 54 (2006) 337-341.

5) H. Kato, K. Yubuta, D. V. Louzguine, A. Inoue and H. S. Kim: Scr. Mater. 51 (2004) 577-581.

6) D. V. Louzguine-Luzgin and A. Inoue: J. Nanosci. Nanotech. 5 (2005) 999-1014.

7) J. Eckert, M. Seidel, U. Klement and L. Schultz: Scr. Mater. 38 (1998) 595-602.

8) Y. K. Xu, H. Ma, J. Xu and E. Ma: Acta Mater. 53 (2005) $1857-$ 1866.

9) G. Q. Xie, D. V. Loouzguine-Luzgin, F. Wakai, H. Kimura and A. Inoue: Appl. phys. Lett. 92 (2008) 121907-3.

10) G. Q. Xie, D. V. Louzguine-Luzgin, H. Kimura and A. Inoue: Mater Trans. 48 (2007) 1600-1604.
11) G. Q. Xie, D. V. Louzguine-Luzgin, H. Kimura and A. Inoue: Intermetallics 18 (2010) 851-858.

12) J. B. Li, J. S. C. Jang, S. R. Jian, K. W. Chen, J. F. Lin and J. C. Huang: Mater. Sci. Eng. A 528 (2011) 8244-8248.

13) J. L. Cheng, G. Chen, F. Xu, Y. L. Du, Y. S. Li and C. T. Liu: Intermetallics 18 (2010) 2425-2430.

14) G. Y. Sun, C. Chen, C. T. Liu and G. L. Chen: Scr. Mater. 55 (2006) 375-378.

15) Z. Amunir, U. Anselmi-Tamburini and J. E. Garay: Mater. Sci. Eng. A 407 (2005) 24-30.

16) G. Q. Xie, D. V. Louzguine-Luzgin, H. Kimura and A. Inoue: Appl. Phys. Lett. 90 (2007) 241902-3.

17) S. Scudino, K. B. Surreddi, H. V. Nguyen, G. Liu, J. S. Kim and J. Eckert: J. Mater. Res. 24 (2009) 2909-2916.

18) K. T. Venkatesara Rao, G. R. Odeet and R. O. Ritchie: Acta Mater. 40 (1992) 253-361.

19) M. M. Trexler and N. N. Thadhani: Prog. Mater. Sci. 55 (2010) 759839.

20) R. D. Conner, R. B. Dandliker and W. L. Johnson: Acta Mater. 46 (1998) 455-468.

21) A. Argon: Acta Metar. 27 (1979) 47-58

22) G. R. Odette, B. L. Chao, J. W. Shechherd and G. E. Lucas: Acta Metall. Mater. 40 (1992) 2381-2389. 